\title{
Sahne Sanatlarının Eşikselliği: Geçiş Ritüelleri Bağlamında Bir Alan Araştırması
}

\section{The Liminality of Performing Arts: A Field Research in Terms of The Rites of Passage}

\author{
Simay YILMAZ ${ }^{1}$
}

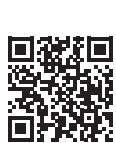

DOI: $10.26650 / C O N S 2020-0001$

${ }^{1}$ Araş. Gör., İstanbul Üniversitesi, Devlet Konservatuvarı, Sahne Sanatları Bölümü, İstanbul, Türkiye

ORCID: S.Y. 0000-0002-3794-4967

\section{Sorumlu yazar/Corresponding author:} Simay Yılmaz,

İstanbul Üniversitesi, Devlet Konservatuvarı, Sahne Sanatları Bölümü, İstanbul, Türkiye E-posta/E-mail: syilmaz1@istanbul.edu.tr

Başvuru/Submitted: 08.05.2020 Revizyon Talebi/Revision Requested: 14.06.2020

Son Revizyon/Last Revision Received: 16.06.2020

Kabul/Accepted: 18.06 .2020

Online Yayın/Published Online: 30.06 .2020

Atıf/Citation: Yilmaz, S. (2020). Sahne sanatlarının eşikselliği: Geçiş ritüelleri bağlamında bir alan araştırması. Konservatoryum - Conservatorium, 7(1), 41-56 https://doi.org/10.26650/CONS2020-0001
Öz

Insan topluluklarının en temel kültürel örüntülerinden olan ritüeller, kültürün araştııımasında en çok başvurulan unsurlardandır. Arnold Van Gennep'in "geçiş ritüelleri" kuramı ve bu kuramın üzerine inşa edilmiş olan Victor Turner'a ait "eşiksellik" kuramı ise, sosyal bilimlerin ritüel çalışmalarının en temel kuramlarıdır. Bu kuramlara göre, hayatın çeşitli aşamalarında ve mecralarında "geçiş ritüelleri" bulunmaktadır ve bu ritüeller üç aşamaya ayrılmış şekilde seyretmektedir. Bu aşamaların ikincisi olan "eşiksel" aşama, bireylerin ne ilk ne de son aşamada olduğu bir 'aradalık' hali ile karakterize olmuştur. Kuramsal tarihi boyunca ritüeller ile benzeştirilmiş, hatta ritüellerin içerisinden doğup salt sanatsal kimliğini kazandığı öne sürülmüş olan sahne sanatları temsilleri, bu çalışmada, ritüellerle olan benzerliğinin değerlendirilmesi amacıyla iki temel ritüel kuramı olan "geçiş ritüelleri" ile "eşiksellik" bağlamında ele alınmıştır. Araştırmada, öncelikle, detaylı bir literatür taraması gerçekleştirilmiş ve kuramsal çerçeve oluşturulmuştur. Daha sonra, oluşturulan kuramsal çerçeve ışığında, sahne sanatları temsillerinin gözlemlendiği ve sahne sanatları çevresi ile birebir görüşmelerin gerçekleştirildiği bir alan araştırması yürütülmüştür. Araştırmanın sonucunda, yüzyıllardır ritüeller ile bir arada ele alınmış olan sahne sanatları temsillerinin hem "geçiş ritüellerinin" üç basamaklı yapısı hem de Victor Turner'ın ikinci aşama üzerine inşa ettiği "eşiksel" evrenin özellikleri ile uyum içerisinde olduğu ve bu kuramlar bağlamında yapılan değerlendirmenin sahne sanatları temsillerinin ritüellerle benzeştiği fikrini pekiştirdiği sonucuna varılmıştır.

Anahtar Kelimeler: Sahne Sanatları, Eşiksellik, Geçiş Ritüelleri

\section{ABSTRACT}

Rituals are one of the most studied concepts in the research of culture. Arnold Van Gennep's theory "rites of passage" and Victor Turner's theory "liminality" are together the most basic theories of ritual studies. According to these theories, there are "transition rituals" at various stages and in various channels of life and these rituals are divided into three stages. The second stage is called "liminality" and is characterized by an 'in-betweenness' in which individuals are neither in the first nor at the last stage. In this study, the field of performing arts, which has always been viewed in terms of rituals and, indeed, is said to be born out of them having gained its purely artistic identity later on, is examined in the context of the "rites of passage" and "liminality" theories, in order to evaluate its similarity with the rituals. After a detailed literature review, this study builds 
a conceptual and theoretical framework for the research. Having done that, we then explain how we conducted our field research which involved participant observation and face-to-face interviews, all in the light of the afore-mentioned framework. The results of the study conclude that performing arts, which have been considered together with rituals since their theoretical beginning, share the principles of the three staged "transition rituals" and the characteristics of the "liminal" stage coined by Victor Turner. The study also concludes that the theoretical framework supports the idea that performing arts are similar to rituals.

Keywords: Performing Arts, Liminality, Rites of Passage

\section{EXTENDED ABSTRACT}

Since the rise and development of social sciences in the nineteenth century, people who share a common culture have been the main focus of the social sciences disciplines. In modern times, in which traditional societies are being changed and transformed, relationships which used to be based on geographical proximity and kinship have been replaced by common interest groups, such as people from similar occupations, similar religions, or ideological groups. These groups possess a common sense of community and a cultural pattern specific to their group just like the groups based on geographical proximity and kinship in traditional societies. The artists and the audience involved in performing arts also form a common culture since they are a common interest group.

Rituals are one of the most studied concepts in the research of culture. Arnold Van Gennep's theory "rites of passage" and Victor Turner's theory "liminality" together compose the most basic theories of ritual studies. According to these theories, there are "transition rituals" at various stages and channels of life and these rituals are divided into three stages. The second stage which is called "liminality", is characterized by an "in-betweenness' in which individuals are neither in the first nor at the last stage. In this study, performing arts, which have always been considered in terms of rituals and are indeed said to be born out of them having gained their purely artistic identity later on, are examined in the context of the "rites of passage" and "liminality" theories in order to evaluate their similarity with rituals. After a detailed literature review, this study builds the conceptual and theoretical framework for its research. Having done that, this paper then outlines the nature of the chosen field research, namely participant observation and face-to-face interviews, which were conducted in the light of the framework outlined earlier in the paper. The results of the study conclude, that performing arts, which have been considered together with rituals since the beginning of their theoretical history, share the principles of the three staged "transition rituals" and the characteristics of the "liminal" stage 
coined by Victor Turner. The study, which was conducted in terms of the above-mentioned theoretical framework, concludes that the idea of performing arts being like rituals can be supported.

The term "performing arts" refers to branches of art which are primarily based on human performance such as theatre, opera and ballet. The instrument used in performing arts is the performer's own body rather than secondary instruments (such as musical instruments). The education in performing arts often starts at a young age but is generally completed at undergraduate and graduate levels in conservatories or other universities in departments such as theatre, opera and ballet. There are periods in the working life of performing artists that affect their daily routines. These are the off-season period, audition periods, rehearsal periods, and the on-stage period. One of the main elements of the performing arts culture is the concept of 'team'. With the people working together in the same project, artists share a sense of a big family experience due to much time being spent together and common goals being shared. Throughout their theoretical history, performing arts have been considered together with rituals. Rituals are social events with features such as formality, sociality and transformativeness. Performing arts, just like rituals, indicate the features of formality, sociality and transformativeness. Milestones in the study of rituals are Arnold Van Gennep's theory of "rites of passage" and Turner's concept of "liminality". French ethnographer Arnold Van Gennep stated that transition rituals had three phases. These are the steps called "separation", "transition" and "integration". Performances of performing arts also possess these three phases. The transition phase, which is the second phase of the transition rituals of Van Gennep, is further examined and detailed by Victor Turner. According to Turner, the participants of a ritual become "communitas", which is the group of "equal and anonymous" individuals in the transition phase. There are a number of features that distinguish these individuals from their normal state. Performing arts events also show these distinguishing features. This article aims to consider performing arts from a social sciences perspective. It is clear, that as long as the "human" is inside, it is appropriate to understand performing arts and other branches of art through the methods and theories of social sciences. 


\section{Giriş}

Ortak bir kültürel örüntü içerisinde yaşayan insan toplulukları, sosyal bilimlerin ortaya çıkıp olgunlaştığı on dokuzuncu yüzyıldan itibaren, alanın ilgi odağını oluşturmuştur. Geleneksel toplumlarda, insanlar, yaşadıkları yer ve akrabalık bağları ile birbirlerine bağlanıp bir kültür meydana getirmektedirler; örneğin bir mahallenin sakinleri veya bir köy halkı. Geleneksel toplum yapılarının değişip dönüştüğü modern zamanda ise, zayıflayan coğrafi ve akrabalık temelli ilişkilerinin yerini mesleki, dini, siyasi vb. temelli ortak ilgi grupları almıştır. Bu gruplar, tıpkı coğrafi yakınlık ve akrabalık temelli gruplar gibi ortak bir topluluk bilincine ve bu topluluğa özgü birtakım kültürel örüntülere sahiptirler. Günümüzdeki kentleşmiş toplumlarda, zayıflamış olan geleneksel akrabalık ilişkilerinin boşalttı̆̆ 1 yeri, ortak ilgi ve meslek grupları gibi alternatif topluluklar almıştır. Etnografik çalışmaların ibresi de coğrafi temelli birliktelik ve kan bağı içerisindeki insan gruplarından (akrabalar, köy sakinleri, kasabalılar vb.), ortak ilgi topluluklarına (meslek grupları, sanat çevreleri, kulüp üyeleri, dini örgütler, sendikalar vb.) çevrilmiştir. Haviland ve diğerlerine göre ortak ilgi grupları, "belirli etkinlikler, hedefler, değerler ya da inançları paylaşan insanların bir araya gelmesi sonucu ortaya çıkan topluluklardır" (Haviland ve diğerleri, 2008, s. 544). Antropolog Meredith Small, arkadaş ve meslek gruplarını geleneksel toplumdaki akraba gruplarının kent toplumundaki muadili olarak görmektedir; ona göre, kent toplumunda akrabaların yerini arkadaşlar ve meslektaşlar, gen ve kan bağının yerini ise beraber geçirilen zaman ve ilgi-görüş ortakllğı almakta, böylece ortak bir paydada buluşulan insan grubuyla geniş bir aile deneyimi yaşanmaktadır (Small, 2000, s. 88).

Güvenç'e göre; "Sosyal ve kültürel antropolojinin konusu, tek kelimeyle, kültür'dür" (Güvenç, 1996, s. 95). İnsan topluluklarının en temel kültürel örüntülerinden biri olan ritüeller ise kültürün araştırılmasında en çok başvurulan unsurlardan biridir. Arnold Van Gennep'in "geçiş ritüelleri” kuramı ve bu kuramın üzerine inşa edilen Victor Turner'a ait "eşiksellik" kuramı sosyal bilimlerin ritüel çalışmalarının en temel kuramlarıdır. Bu kuramlara göre, hayatın çeşitli aşamalarında ve mecralarında ritüeller bulunmaktadır, bu ritüeller üç aşamaya ayrılmıştır ve bu aşamaların ikincisi olan "eşiksel" aşama, bireylerin ne ilk ne de son aşamada olduğu bir 'aradalık' hali ile karakterize olmuştur. Kuramsal tarihi boyunca ritüeller ile benzeştirilmiş, hatta ritüellerin içerisinden doğup salt sanatsal kimliğini kazandığı öne sürülmüş olan sahne sanatları temsilleri (Brockett ve Hildy, 2016, s. 1), bu çalışmada, ritüellerle olan benzerliğinin değerlendirilmesi amacıyla iki temel ritüel kuramı olan "geçiş ritüelleri" ile "eşiksellik" bağlamında ele alınmıştır. 
Araştırmada, sosyal antropoloji disiplininin benimsediği yöntem ve tekniklere başvurulmuştur. Öncelikle, araştırma konusu ile ilgili literatür dikkatlice taranmış, kavramsal ve kuramsal çerçeve belirlenmiştir. Literatür taraması ve alanı tanıyarak geçirilen süre sonucunda alanda kullanılacak sorular ve görüşülecek konular belirlenmiş ve görüşme rehber formları hazırlanmıştır. Daha sonra, oluşturulan kavramsal ve kuramsal çerçeve ışı̆̆ında bir alan araştırması gerçekleştirilmiştir. Alan araştırması, derinlemesine görüşmeler ve katılımcı gözlem teknikleriyle yürütülmüştür. Katılımcı gözlem dâhilinde, araştırmanın konusunu oluşturan sahne sanatlarının provalarına, temsillerine ve sanatçıların günlük yaşam faaliyetlerine katılım gösterilmiş, sanatçılar ve izleyenlerle konu hakkında soruların sorulduğu derinlemesine görüşmeler gerçekleştirilmiştir. İstanbul Avrupa yakasındaki iki özel sahne sanatları tiyatrosu, Anadolu yakasındaki bir alternatif tiyatro ve iki konser-bale salonundaki projelerde çalışmakta olan sanatçılar ve araştırmanın yürütüldüğü dönemde bir projede çalışmıyor olan çeşitli sanatçılar ve izleyicilerin oluşturduğu 30 kişi (bale, opera, tiyatro sanatçıları ile izleyicileri) ile yürütülen alan araştırması, 2018'in Eylül ayı ile 2019'un Haziran ayı arasındaki 10 aylık süreyi kapsamıştır. Görüşmeler yoluyla elde edilen veriler, makale içerisinde görüşülenlerin adları gizlenip alanlarına göre kodlanarak ifade edilmiştir. ${ }^{1}$ Yapılan görüşmeler içerisinden makalede örnek verilmek üzere kullanılan alıntıların sahipleri makale içerisinde şu şekilde kodlanmıştır: Bale sanatçıları B-1 ve B-2; tiyatro sanatçısı T-5; izleyiciler İ-1 ve İ-2. Araştırmanın örneklemini kartopu örneklem olmuştur. Kartopu örneklem, "araştırma alanında kaynak kişilerden doğru diğer görüşülecek kişilere ulaşılması ve bir kartopu gibi, ilerledikçe yeni kişilere ulaşıldıkça örneklemin büyümesi ile oluşmasıdır” (Kümbetoğlu, 2012, s. 99).

Her disiplinin tanıdığ etik standartlar, araştırmacıların uyduğu etik kurallar bulunmaktadır. Doğa bilimlerinde olduğu gibi sosyal bilimlerde de etik standartlar ve sorunsallar bulunmaktadır, hatta söz konusu sosyal bilimlerin inceleme konusu insan olunca bu etik unsurlar daha da çetrefilli bir hal almış, üzerine uzun tartışmalar yapılmıştır. İnsan ile çalışmak, laboratuvar ortamında kesin sonuçlar alınan bir deney yürütmekten farklıdır: "[...] inceleme konuları olan insanın toplumsal yaşamının akıcı, gözlemlenmesi güç ve laboratuvar araçlarıyla kesin olarak ölçülmesinin zor oluşudur” (Neuman, 2006, s. 10). $\mathrm{Bu}$ sebeple araştırmaların güvenilirliği ve gerçeği temsil etmesi konusunda elimizde

1 Alan araştırmasının yürütüldüğü kişilerden isminin baş harflerinin kullanılmasına izin verenler ile araştırma yayınında kullanılmak üzere kod isim tercih edenlerin listesi şu şekildedir: Bale sanatçıları E.Ç., S.İ., H.Ü., Zeynep, İ.A., Aleyna, Ö.T.; opera sanatçıları U.T., A.Z., U.S., Tenor, S.A., A.Y.; tiyatro sanatçıları S.A., Y.E., A.Y., M.G., Ali, S.B., T.C., Pelin, E.Ş., S.Y., Y.S., S.Ş.; izleyiciler M.K., S.Y., B.S., N.Ş., A.E.. 
araştırmacıya güven duymak dışında bir seçenek bulunmamaktadır. Bu da araştırmacının bir dizi sorumluluğun farkında olmasını gerektirir. Antropolog alanda, alandan sonraki raporlama sürecinde ve belki de hayatının sonuna kadar araştırdığı topluluğu en doğru şekilde anlatmak, güvenlerini kırmamak, bilgileri çarpıtmamak, eksik veya fazla söylememek ile görevlidir. Bu araştırma sırasında da bu etik unsurlara dikkat edilmiştir. Alana girilen ilk andan itibaren görüşülenler ve aralarında zaman geçirilen sanatçılar ve izleyicilere bir araştırma sürecinde olunduğu bildirilmiş ve bu kişiler araştırmanın konusu hakkında bilgilendirilmiştir. Araştırmaya katılmak istemeyen kişiler hakkında gözlem veya kayıt yapılmamıştır. Görüşülen kişiler, ses kaydı alınması ve not tutulması konusunda önceden bilgilendirilmiş, izin vermemeleri halinde ise asla kendilerinden gizli ses kaydı alınmamış veya not tutulmamıştır.

\section{Genel Bir Bakıș: Sahne Sanatları}

Sahne sanatları, İngilizce'de performing arts, Almanca'da Bühnenkünste olarak adland1rılan alanın (Pavis ve Shantz, 1999, s. 262) Türkçe'deki adıdır. İngilizce performing arts terimi, tamamen başka bir alana işaret eden performance art ile karıştıılmamalıdır. Performance Art, Türkçe'de “performans sanatı” olarak karşılık bulmaktadır (Çalışlar, 1995, s. 496). Sahne sanatları terimi, performans sergilemeye dayalı sanat dalları olan tiyatro, opera ve bale gibi sahne üzerindeki enstrümanın ikincil enstrümanlar yerine (müzik aletleri gibi), insanın kendi bedeninin olduğu sese, oyunculuğa ve dansa dayalı ve daha önceden prova edilen bir yapının sunulduğu sanat çeşitlerine işaret etmektedir. Royce, Anthropology of the Performing Arts isimli kitabında sahne sanatlarının temelde üç performans çeşidi ve bunların kombinasyonlarından oluştuğunu aktarmaktadır: "Sahne sanatları, özellikle müzik, dans, tiyatro ve bu türlerin kombinasyonlarıdır” (Royce, 2004, s. 1).

Sahne sanatları, özel ve yoğun bir eğitim süreci gerektiren bir alandır. Çoğu zaman sahne sanatları alanına adım atmayı isteyen gençlerin, küçük yaştan itibaren birtakım pratikler kazanmak için alıştırmalar yapmaya başlamaları gerekmektedir. Türkiye'de, konservatuvarların veya diğer üniversitelerin tiyatro, şan ve dans bölümlerinde eğitim gören sanatçıların lisans eğitimleri, bölümden bölüme ve konservatuvarlar ile diğer üniversiteler arasında değişiklik göstererek 4 ila 6 öğretim yılı arasında sürmektedir. Sanatçı adayları, lisans seviyesindeki eğitimlerinin öncesinde, lise eğitimleri süresince güzel sanatlar liselerinde öğrenim görerek veya güzel sanatlar lisesi dışında bir lisede öğrenim görürken bir kursa devam ederek, sanat dallarına yönelik ilk öğrenimlerini gerçekleştirmeye baş- 
larlar. Kimi durumlarda, örneğin lisans eğitimi bale üzerine olan sanatçılar örneğinde, bu lisans öncesi eğitim süreci ilkokul hatta anaokulu yaşlarına kadar inmektedir:

\footnotetext{
"Ben bir konservatuvarın bale bölümünden mezunum, ama öncesi de var. Yani zaten bizde bale yapıyor olarak girersin lisansa. Ben 5 yaşından beri bale yapıyorum, lisede de konservatuvarın bale bölümünde okudum. Sanırım bale bölümü diğer dans bölümlerinden biraz daha katı bu konuda, ön eğitimin olmadan lisans seviyesinde baleye kabul edilmek biraz zor" (B-1, kişisel iletişim, 02.11.2018).
}

Yapılan gözlem ve görüşmelere göre, sahne sanatları çalışma hayatında sanatçıların günlük rutinlerini etkileyen dönemler bulunmaktadır. Bunlar, sezon dışı dönem, seçme dönemi, prova dönemi ve temsil dönemidir. Sezon dışı dönem, sahne sanatları gösterilerine ara verilen yaz aylarına işaret etmektedir. Bu dönemin sanatçı tarafindan nasıl deneyimlendiğinin, sanatçının bir kurumda kadrolu olarak düzenli maaş ile veya proje başına sözleşme imzalayarak temsil başına ödeme ile çalışmasıyla yüksek oranda alakalı olduğu gözlemlenmiştir. Seçme günleri, prova dönemi ve temsil dönemi ise; ayırt etmeksizin her sanatçı için benzer dinamiklere sahiptir. Sanatçıların bir projeye dahil olmaları, seçme süreçleri ile başlamaktadır. Seçme süreçleri, genellikle uzun saatler süren, fiziksel ve psikolojik olarak zinde olmayı gerektiren süreçlerdir. Projede yer alacak sanatçıların bu seçme sürecinde belirlenmesinden projenin sahnelemesine kadar geçen süre prova sürecidir. Bu süreç, projeden projeye değişkenlik göstermekle birlikte, alan araştırması sırasında denk gelinen projeler için bu süre 2-3 ay kadar sürmüştür. Prova süreci genel olarak bir toplantı ile başlamaktadır. Bu toplantıda sanatçılar prova tarihlerini, şartlarını, planlanan temsil süresini öğrenir ve sözleşmelerini imzalarlar. Bir pürüz çıkmadı̆̆g takdirde, provalar planlanan sürede biter ve temsil dönemine geçilir, ancak kimi zaman temsillerin başlamasından sonra devam eden hatırlama provaları da yapılmaktadır. $\mathrm{Bu}$ süreç, sanatçıların kendilerine dikkat etmeleri gereken bir dönemdir. Araştırma sırasında görüşülen bir bale sanatçısı, temsil döneminde saçlarını asla ıslak bırakmadığını aktarmıştır. Ona göre, temsiller devam ettiği sürece ıslak saçla üşütüp hasta olma 'lüksü’ bulunmamaktadır. (B-2, kişisel iletişim, 02.11.2018). Temsil günlerinde, sanatçılar, temsil saatlerinden en az iki saat önce sahneye gelirler. Genellikle, saç ve makyaj konusunda yetenekli olan bir kişi diğer sanatçılara yardım eder, çünkü şartları çok iyi olanlar dışındaki kurumlarda nadiren kuaför ve makyöz bulunur veya var olan kişi herkese yetişmekte zorlanır. Temsil kostümleri, sahneler arasında hızlı değişim yapılacaksa kolayca giyilebilecek şekilde asılır ve bu alan oyun sırasında karışıklık yaratmayacak şekilde 
düzenlenir. Hazırlıklar bittikten sonra, salon ışıkları alınır ve temsil başlar. Bu rutin, sezonun kapanmasına kadar, projeden projeye değişiklik göstererek ayda birden gün aşırıya kadar değişen bir yoğunlukta tekrarlanır.

\section{Ritüel Kavramı ve Sahne Sanatları}

Ritüeller, kültürün en temel yapıtaşlarındandır. Özbudun ve Uysal, ritüellerin günlük hayattaki eylemlerden ayırt edici özelliklerini şu şekilde sıralamışlardır: Biçimsellik, toplumsallık, bilgilendiricilik, meşrulaştırıcılık ve dönüştürücülük. Bu özelliklerden biçimsellik, ayinlerin belirli zaman ve belirli mekânlarda, sabit söz ve eylem dizileri ile tekrar edilir olmasına; toplumsallık, ayinlerin bireysel değil toplu olarak icra edildiğine; bilgilendiricilik, ayinlerin katılımcılarını inanç sistemlerine dair bilgilendirdiğine; meşrulaştırıcılık, ayinlerin toplumdaki mevcut yapıyı pekiştirdiğine; dönüştürücülük ise, ayin katılımcılarının gündelik hallerinden farklı bir boyuta dönüşmelerine işaret etmektedir (Özbudun ve Uysal, 2012, s. 182).

Sahne sanatları, kuramsal tarihleri boyunca ritüeller ile benzerlik içerisinde ele alınmıştır, sahne sanatlarının ritüellerin içinden doğup zamanla kendine özgü salt sanatsal kimliğini kazandığ1 yaygın bir görüştür (Brockett ve Hildy, 2016, s. 1). Sahne sanatlarının seyirci ile sanatçıyı bir araya getiren sunuş alanı temsillerdir. Bu temsiller, ritüellerin yukarıda sıralanan karakteristik özelliklerine göre ele alındığında özellikle üç unsur, sahne sanatları temsillerinde fazlasıyla ön planda oluşu ile göze çarpacaktır: Biçimsellik, toplumsallık ve de en önemlisi dönüştürücülük. Diğer iki özellik olan bilgilendiricilik ve meşrulaştırıcıllk işlevleri, sanatın salt sanatsal kimliğini kazanması ile ritüellerin dini temelli olduğu ayin formlarına özgü birer toplumsal işlev olarak geride kalmış gibi gözükmektedir. Biçimsellik, toplumsallık ve dönüştürücülük unsurlarını sahne sanatları özelinde ele almak gerekirse:

Sahne sanatları temsilleri, ritüellerin belirli zaman ve belirli mekânlarda, sabit söz ve eylem dizileri ile tekrar edilir olmasına işaret eden 'biçimsellik' özelliği bağlamında incelendiğinde; temsillerin, tıpk1 ritüeller gibi belirli zaman (temsil günü ve saati bellidir) ve belirli mekânlarda (temsilin yapılacağı sahne bellidir), sabit söz ve eylem dizileri ile (temsillerde replikler, şarkı sözleri ve notaları, dans koreografisi ve hareket düzeni belirli ve sabittir, temsilden temsile değişmez) ve tekrar edilebilir olarak (bir mezuniyet temsili olmadığı sürece her temsil tekrar tekrar sahnelenmektedir) gerçekleştirildiği gözlemlenmiştir. Dolayısıyla, sahne sanatları temsilleri biçimsellikleri bağlamında ritüeller ile tam bir uyum içerisindedirler. 
Sahne sanatları temsilleri, ritüellerin bireysel değil toplu olarak icra edilişine işaret eden 'toplumsallık' özelliği bağlamında incelendiğinde; bu temsillerin, tıpkı ritüeller gibi toplu olarak icra edildiği gözlemlenmiştir. Hem sanatçıların hem seyircilerin temsil günü ve saatinde etkinlik mekânına topluca katılımları ve sahne üzerinde sunulan ile seyirci arasında bir etkileşim ve seyirciden gelen bir reaksiyon olması, temsillerin toplumsallığını ortaya koymaktadır. Dolayısıyla, sahne sanatları temsilleri toplumsallıkları bağlamında da ritüeller ile tam bir uyum içerisindedirler.

Sahne sanatları temsilleri, ritüellerin katılımcılarının gündelik hallerinden farklı bir boyuta dönüşmelerine işaret eden 'dönüştürücülük' özelliği bağlamında incelendiğinde hem sahne üzerindeki sanatçıların hem de izleyenlerin temsillerden temsil öncesindeki hallerinden farklılaşmış şekilde ayrıldıkları gözlemlenmiştir. Görünen o ki, bu, temsiller sırasında sahne üstünde ve seyirci koltuklarında gerçekleşen karşılıklı alışveriş, duygusal ve düşünsel yolculuk sebebiyle yaşanmaktadır. Bu bağlamda sahne sanatları, ritüellerin dönüştürücülük özelliğini de kendi bünyesinde barındırmaktadır.

Daha önce de belirtildiği üzere, ritüellerin diğer iki özelliği olan bilgilendiricilik ve meşrulaştırıcılık işlevleri, halen kimi yaratımlarda kendine yer bulmakla birlikte, sanatın salt sanatsal kimliğini kazanmasının ardından ritüellerin din temelli olduğu ayin formlarına özgü birer toplumsal işlev olarak geride kalmış gibi gözükmektedir.

Ritüeller pek çok antropolog tarafından, farklı kuramlar bağlamında çalışılmıştır. Ancak din antropolojisi alanındaki ritüel çalışmalarında dönüm noktası Arnold Van Gennep'in “geçiş ritüelleri” kuramı ve Turner'ın bu kuramın “eşiksel” evresi üzerine inşa ettikleri olmuştur. Sıradaki alt başlıklar altında, sahne sanatları temsilleri, yapılan gözlem ve görüşmeler 1şı̆̆ında bu iki ritüel kuramı bağlamında değerlendirilecektir:

\section{Geçiş Ritüelleri ve Sahne Sanatları Temsilleri}

Fransız etnograf Arnold Van Gennep, geçiş ritüellerinin üç basamaklı olduğundan bahsetmektedir. Bunlar, "ayrılma/eşiksellik öncesi” (separation/preliminal), "geçiş/eşiksellik" (transition/liminal) ve "bütünleşme/eşiksellik sonrası" (reaggregation/postliminal) isimli basamaklardır (Van Gennep, 1960). Doç. Dr. Sibel Özbudun ve Doç. Dr. Gülfem Uysal, bu basamakları şu şekilde açıklamaktadırlar:

“Ayrılma evresi, kişi ya da grubun eski halinden, konumundan vb. kopuşunu simgeleyen edimlerle karakterize olmaktadır. [...] Eşiksellik evresi, kişinin 'ne orada, ne burada' oldu- 
ğu ikircim ve belirsizlik yüklü bir durumu simgeler. [...] Bütünleşme evresi ise, bireyin ya da grubun dönüşüme uğramış olarak topluma yeniden katıldığı evredir”" (Özbudun ve Uysal, 2012, s. 184).

Ayrılma evresinde, kişi veya kişilerin mevcut durumlarından zamansal ve mekânsal olarak ayrılması söz konusudur. Gündelik hayatın sürüldüğü mekândan ritüel için özel olarak belirlenmiş bir mekâna geçilir ve zamansal olarak da ayinsel zaman, günlük sıradan zamandan ayırt edilir. Turner'a göre, ayrılmanın ilk aşaması, açıkça, günlük mekândan ve zamandan kutsal alan ve zamana geçmek üzere ayrılmayı gösterir (Turner, 1982, s. 24). İkinci evre olan geçiş evresinde, söz konusu ritüel gerçekleşir. Burada, önceki basamak olan ayrılma evresinden sonraki evre olan bütünleşme evresine geçiş gerçekleşmektedir. Ayrılma ve bütünleşme evrelerinin ortasında bulunan geçiş evresi, Victor Turner tarafından bir sonraki bölümde incelenecek olan "eşiksel” evre olarak tanımlanmıştır. Turner, bu evre üzerine, kendisine ait olan liminality (eşiksellik) ve communitas kavramlarını inşa etmiştir. Son evre olan bütünleşme evresinde ise, normal zaman ve mekâna dönüş söz konusudur. Dönüşüm yaşamış olan bireyler normal hayatın akışına dönüşmüş olarak dahil olmaktadırlar.

Gerçekleştirilen gözlem ve görüşmeler 1şığında, geçiş ritüellerinin bu üç evresinin sahne sanatları temsillerini ne ölçüde temsil ettiği incelendiğinde şu sonuçlara varılmıştır: Geçiş ritüelleri üç evreden oluşmaktadır, ayrılma, geçiş ve bütünleşme evreleri; sahne sanatları temsilleri de hem sanatçılar hem izleyenler için, temsil öncesi, temsil ve temsil sonrası olarak üç evrede ele alınabilmektedir.

Birinci evre olan 'ayrılma' evresinde, Van Gennep'e göre, bireyler, normalde ait oldukları günlük hayatın zamansal akışı ve mekânlarından, gerçekleşecek ritüele katılmak üzere 'ayrılırlar' ve bu ritüel için belirlenmiş zamanda, bu ritüel için belirlenmiş mekâna gelirler. Sahne sanatları temsilleri açısından da bu evre geçerli olduğu gözlemlenmiştir: Hem sanatçılar hem izleyenler, günlük hayatlarından ayrılıp, temsil için belirlenmiş zamanda, temsil için belirlenmiş sahneye gelirler. Sanatçılar ve izleyenler, az sonra anonim sanatçılar ve anonim izleyenler olarak katılacakları temsilin başlamasından hemen önce, son defa kendi kimlikleri ve normal hayatın akışına ait olarak kulislerinde ve fuayede temsilin başlamasını beklerler.

İkinci evre olan 'geçiş’ evresinde, Van Gennep'e göre, söz konusu ritüel gerçekleşir. Sahne sanatları temsilleri de bir ritüelin sahip olduğu biçimsellik, toplumsallık ve dönüş- 
türücülük özelliklerini bünyesinde barındıran bir olay olarak ritüellerle benzerlik içerisinde gerçekleşir. Normal zaman ve mekânın dışına çıkılır hem sanatçı hem izleyenler, sahne üzerindeki zaman ve mekâna adapte olur. Belirli zaman ve belirli mekânlarda, sabit söz ve eylem dizileri ile ve tekrar edilebilir olarak gerçekleşen temsile topluca kat1lım söz konusudur.

Üçüncü evre olan ‘bütünleşme’ evresinde, Van Gennep’e göre, normal zaman ve mekâna dönüş söz konusudur. Bireyler normal hayatın akışına, dönüşmüş birer birey olarak dahil olurlar. Sahne sanatları temsillerinin sonunda da tıpkı ritüellerin bütünleşme evresinde olduğu gibi, sanatçılar sahneyi, seyirciler izleyici koltuklarını terk eder ve normal hayat ile yeniden buluştukları kulislerine ve fuayeye geçerler.

Görünen o ki sahne sanatları ritüelleri, geçiş ritüellerinin üç evreli yapısı ile benzerlik içerisinde gerçekleşmektedir. Van Gennep'in geçiş ritüellerinin ikinci evresi olan ve ritüelin gerçekleştiği evreyi temsil eden geçiş evresi, Turner tarafından daha da derinlemesine incelenmiş ve detaylandırılmıştır. Sıradaki başlık altında, Turner'ın geçiş evresi üzerine yapılandırdığı "eşiksellik" kuramı açıklanacak ve sahne sanatları temsilleri bu kuram bağlamında incelenecektir.

\section{Eşiksellik Kavramı ve Sahne Sanatlarının Eşikselliği}

İngiliz antropolog Victor Turner, Zambiya'da yaşayan Ndembu kabilesinin ayinleri üzerine çalışırken Van Gennep'in geçiş ayinleri basamaklarının özellikle 'eşiksellik' evresinde yoğunlaşmış ve bu evredeki eşit bireyler topluluğunu işaret ettiği communitas kavramını oluşturmuştur (Turner, 1977). Turner'a göre (Turner, 1982), eşiksel evredeki bireyler, eski hallerinden ayrılmış ve yeni hallerine henüz dönüşmemişlerdir; yani Özbudun ve Uysal'ın deyimiyle "ne orada ne burada" oldukları belirsiz bir durum içerisindelerdir (Özbudun ve Uysal, 2012, s. 184).

Turner'a göre, ritüelin katılımcıları, eşiksel evrede, 'eşit ve anonim' bireyler topluluğu olan communitas'a dönüşmektedirler. Communitas içerisindeki bireyleri normaldeki hallerinden ayıran bir dizi özellik bulunmaktadır: Mevcut yapıdakinin aksine, eşiksellik evresinde; hiyerarşinin yerini eşitlik, mülkiyetin yerini mülksüzlük, cinsel normların yerini cinsel perhiz ya da cinsel aşırılık, gündelik kıyafetlerin yerini üniforma, kişilerin yerini anonimlik alır (Özbudun ve Uysal, 2012, s. 185). Turner'ın açılımını yaptığı eşiksellik evresinde katılımcı bireylerin dönüştügü communitas kavramının sahne sanatları 
temsilleri katılımcılarını ne ölçüde ifade ettiği yapılan gözlem ve görüşmeler ile incelendiğinde şu sonuçlara varılmıştır:

Sahne sanatları temsilleri, geçiş ritüelleri karakteristiğine sahiptir ve temsiller sırasında hem izleyiciler hem sanatçılar tarafından, geçiş ritüellerinin ikinci aşaması üzerine Turner'ın inşa ettiği eşiksel evre deneyimlenmektedir. Özbudun ve Uysal'ın belirttiği üzere, bu eşiksel evrede, ilk olarak hiyerarşinin yerini eşitlik almaktadır (Özbudun ve Uysal, 2012, s. 185). Eşiksel evrenin bu ilk özelliği sahne sanatları temsilleri bağlamında ele alındığında, gerçekten de temsiller sırasında normal hayattaki hiyerarşilerin önemi kalmadığı gözlemlenmiştir. Örnek vermek gerekirse, yapılan gözlem ve görüşmelerde görülmüştür ki, normal hayattaki hiyerarşide bir başkasından 'üstün' bir sosyal statü ile karakterize olan bir sanatçı, sahnelenen eserde diğer sanatçılar ile sahne üzerinde aynı işi yapmakta ve hatta daha küçük roller oynayıp daha kısa şarkılar söyleyebilmektedir. İzleyenler açısından ele alındığında ise, yine normal hayattaki hiyerarşi içerisinde farklı sosyal katmanlar ile karakterize olmuş kişiler, yan yana alınan bilet numaraları ile temsil süresince yan yana oturabilmektedirler ve sahne üzerindeki temsil bir kişiye farklı bir başkasına farklı şekilde icra edilmemektedir. Bilet ücretine göre sahneye yakınlığın ayarlanabildiği kurumlarda bile iki farklı toplumsal sınıftan iki izleyici birkaç oturma sırası arayla aynı oyunu, gösteriyi, konseri izlemektedir. Temsillerde sahne üzerindeki herkes 'sanatçıdır', izleyen herkes ise 'izleyici'. Bu bağlamda, ortaya şu sonuç çıkmaktadır ki ritüellerin eşiksel evresine paralel olarak sahne sanatları temsillerinde de günlük hayattaki hiyerarşinin yerini eşitlik almaktadır.

Özbudun ve Uysal'ın Turner'ın eşiksellik kuramına ilişkin çalışmasından (Turner, 1977) aktardığ üzere, eşiksel evrede, mülkiyetin yerini mülksüzlük almaktadır (Özbudun ve Uysal, 2012, s. 185). Eşiksel evreye ait bu unsurun da temsiller için son derece geçerli olduğu gözlemlenmiştir: Hem sanatçılar hem de izleyenler kendilerine ait bir mülkte değil başka bir ortak alandadırlar ve hem sahnede hem de izleyici koltuklarında kişilerin mülkleri normal hayatta geri dönmek üzere geride kalmıştır.

Eşiksel evrenin üçüncü özelliği, cinsel normların yerini cinsel perhiz ya da cinsel aşırıllğın almasıdır (Özbudun ve Uysal, 2012, s. 185), Eşiksel evrenin bu üçüncü özelliği sahne sanatları temsilleri bağlamında ele alındığında, temsiller sırasında da normal hayattaki normların aynı şekilde algılanmadıkları gözlemlenmiştir. Hem cinsel normlar hem de diğer toplumsal normlar, sahnelerde artık norm olmaktan çıkarlar. Sahne üzerinde ger- 
çekleşen kurgu, günlük hayatta olduğu gibi yadırganmamakta, ayıplanmamakta veya bu kurgunun bir yaptırımı olmamaktadır, izleyen herkes sahne üzerinde gerçekleşenin kurgunun bir parçası olduğunun bilincindedir. Örnek vermek gerekirse, bir izleyici, sahnelenen oyun kapsamında izlenilen cinayet sahnesi ile ilgili şu yorumu yapmıştır: "Ben orada olanın gerçek olmadığını biliyorum tabi. Normalde böyle bir şeye seyirci kalmazsın, ama burada oturup izliyorsun. Aslında şimdi düşününce garip geldi [Güler]" (İ-2, kişisel iletişim, 12.11.2018).

Eşiksel evrede katılımcıların deneyimlediği bir diğer özellik, gündelik kıyafetlerin yerini üniformanın almasıdır (Özbudun ve Uysal, 2012, s. 185). Burada kastedilen, elbette ki o ayin veya ritüele özel birer kıyafetin giyilmesidir. Sahne sanatları bağlamında bakıldı̆̆ında hem sanatçılar hem de izleyenler temsile özel birer 'üniforma' giymektedirler. Sanatçılar, günlük hayattaki kıyafetlerinden farklı olan sahne kostümlerini giymekte, izleyenler ise bir tiyatro, opera veya bale binasında giyilmeye uygun kıyafetler giymektedirler. Özellikle opera ve bale gibi elitizmin yüksek olduğu sanat dallarında, izleyiciler çoğu zaman koyu renkte resmi veya şık kıyafetler tercih etmektedirler. Bu zorunlu olmasa dahi, görünmeyen ve yazılı olmayan bir 'temsile katılmaya uygun düşen kıyafet' bilinci bulunmaktadır ve bu sanat çevresi tarafından pekâlâ farkında olunan bir gelenek ve görenektir. Bu konu ile ilgili gerçekleştirilen görüşmelerde bir izleyiciden şu cevap alınmıştır:

\footnotetext{
“Tabi ki bir kıyafet adabı olur. Bir gömlek giyer en azından erkekler. Kadınlar da şı şeyler tercih ederler. Dışarıdaki salaş kıyafetinle gelinmez. Eskiden çok daha yaygın bir görgü kuralıydı, şimdilerde şortla gelen bile oluyor. Ama olmaması lazım. Biz ailecek çok dikkat ederiz, çocuğumuza da aşılamaya çalıştığımız bir görgü kuralı” (İ-1, kişisel iletişim, 23.05.2019).
}

Özbudun ve Uysal'ın aktardığı üzere (Özbudun ve Uysal, 2012, s. 185), eşiksel evrede katılımcıların deneyimlediği bir diğer özellik, kişilerin yerini anonimliğin almasıdır. $\mathrm{Bu}$ unsur, ritüel katılımcılarının günlük hayattaki sosyal statü, isim, maddi varlık, ilişkiler ağ $1 \mathrm{vb}$. hiçbir şeyinin ritüel anında görünür olmadığına işaret etmektedir. Ritüellere ait bu özelliğin, sahne sanatları temsillerinde diğer unsurların hepsinden daha güçlü bir şekilde var olduğu gözlemlenmiştir. Temsillerde sahne üzerinde, sanatçılar izleyenler tarafından anonim bireyler olarak görülmektedir. Bu kişilerin canlandırdıkları karakter dışındaki kişilik özellikleri, maddi ve manevi varlıkları, sahip oldukları kişiler ağı vb. özellikleri sahne üzerinde görünür değildir. Sahne üzerinden bakanlar ise karşılarında 
anonim izleyiciler görmektedirler, aynı şekilde izleyenlerin bireysel özellikleri ve kim olduklarının da görünürlüğü kalmamıştır. Sanatçılar, sahne üzerinde bir topluluğun anonim bireyleri olarak temsile göre özelleştirilmiş görüntüleriyle performanslarını sergilerken, sahnenin ardında isimlerini, kimliklerini ve 'off-stage' hayatlarını geri yüklenmektedirler. İzleyiciler de aynı şekilde, dışarıdaki hayatlarından arınmış bireyler olarak temsili izledikten sonra fuayede isimlerini, kimliklerini ve günlük hayatlarını geri yüklenmektedirler. Bu konu ile ilgili gerçekleştirilen görüşmelerden birinde bir bale sanatç1sından konuyla ilgili şu yorum gelmiştir: "Standart gözükmemiz çok önemli. Biz aşırı kilo alamayız örneğin, normalden çok fazla farklılaşamayız. Sahnede birbiriyle aynı gözüken balerinleriz; Ayşe, Fatma, Zeynep değil. Kimliklerimiz perdenin arkasında" (B-2, kişisel iletişim, 02.11.2018).

Sanatçılar, sahne üzerinde bireysel özelliklerinden sıyrılmakta, anonim bireyler haline dönüşmektedirler. Sahne üzerindeki eşiksellik hali son bulduğunda ise sanatçılar kendi isimleri ve kimliklerini geri yüklenip, sahne ardındaki hayatlarına katılmaktadırlar. Görüşülen bir tiyatro sanatçısı bu konuyu şu şekilde yorumlamıştır: "Ben sahnede Kral Lear oynuyorum örneğin, ama evde pijamayla temizlik yapıyorum. [Gülüyor] Sahneye çıktığımda farklı bir 'ben' var, hatta orada artık 'ben' yok, büyük bir şeyin, ekibin parçasıyım" (T-5, kişisel iletişim, 12.11.2018).

İncelenen örnekler ve yapılan gözlemler neticesinde görünen odur ki, sahne sanatları temsilleri, barındırdıkları özellikler ile Turner'ın geçiş evresinin eşiksel bir süreç olduğu ve bu evrede katılımcıların normal hayatlarından farklı anonim özellikler giyinen communitas'a dönüştükleri önerisi ile örtüşmektedirler. Bu temsillerde hem sahne üstünde hem izleyici koltuğundakiler, topluca katılımda bulundukları bir etkinlikte, dışarıdaki hayatlarında kim olduklarının önemi kalmadan, zamansal ve mekânsal işleyiş̧en kopup, anonim bireyler olarak topluca bir dönüşüm yaşamaktadırlar ve communitas kavramının getirdiği üniforma, anonimlik, normların etkisizleşmesi vb. bir dizi unsura uygun hareket etmektedirler.

\section{Sonuç}

Geleneksel toplumlarda akrabalık ve coğrafi yakınlık üzerine kurulmuş olan ortak kültüre sahip insan toplulukları arasındaki bağın modern toplum yapısında zayıflamasıyla, bu toplulukların yerini bireylerin ortak ilgilerinin ön planda olduğu mesleki, dini, siyasi gruplar veya hobi grupları almıştır. Modern toplumda ortaya çıkan ortak ilgi grupları, tıpkı geleneksel toplumdaki coğrafi yakınlığa veya akrabalığa dayalı gruplar gibi, ortak bir kültüre 
sahiptirler. Bu sebeple, ortak kültüre sahip insan gruplarının incelenmesini odak noktasına koyan antropoloji, sosyoloji gibi disiplinler, modern zamanda ibrelerini ortak ilgi gruplar1na çevirmişlerdir ve artık şehrin arka sokaklarındaki müzik kültürü, alternatif tiyatrolar gibi görece yeni ve ortak bir kültürün bireylerini barındıran gruplar incelenmeye başlanmıştır. Sahne sanatları terimi, performans sergilemeye dayalı sanat dalları olan tiyatro, opera ve bale gibi sahne üzerindeki enstrümanın ikincil enstrümanlar yerine (müzik aletleri gibi), insanın kendi bedeninin olduğu sese, oyunculuğa ve dansa dayalı ve daha önceden prova edilen bir yapının sunulduğu sanat çeşitlerine işaret etmektedir.

İnsan topluluklarının en temel kültürel örüntülerinden biri olan ritüeller, kültürün araştırılmasında en çok başvurulan unsurlardan biridir. Arnold Van Gennep'in "geçiş ritüelleri” kuramı ve bu kuramın üzerine inşa edilen Victor Turner'a ait “eşiksellik" kuramı ise sosyal bilimlerin ritüel çalışmalarının en temel kuramlarıdır. Kuramsal tarihi boyunca ritüeller ile benzeştirilmiş, hatta ritüellerin içerisinden doğup salt sanatsal kimliğini kazandığı öne sürülmüş olan sahne sanatları temsilleri, bu çalışmada, ritüellerle olan benzerliğinin değerlendirilmesi amacıyla iki temel ritüel kuramı olan "geçiş ritüelleri” ile "eşiksellik" bağlamında ele alınmıştır.

Ritüeller; biçimsellik, toplumsallık, dönüştürücülük gibi özelliklere sahip toplumsal olaylardır. Sahne sanatları temsilleri, tıpkı ritüeller gibi belirli ve belirli mekânlarda, sabit söz ve eylem dizileriyle ve tekrar edilebilir olarak gerçekleştirilmesi bakımından ritüellerin biçimsellik özelliği ile; hem sanatçıların hem seyircilerin temsil günü ve saatinde etkinlik mekânına topluca katılımları bakımından toplumsallık özelliği ile; temsil sırasında sahne ile seyirci koltukları arasında gerçekleşen karşılıklı alışveriş neticesinde hem sahne üzerindeki sanatçılar hem de izleyenlerin, temsilden, önceki hallerinden farklılaşmış şekilde çıkmaları bakımından ise dönüştürücülük özelliği ile uyum içerisindedir.

Araştırmada görüldüğü üzere, sahne sanatları temsilleri, ritüel çalışmalarına ilişkin "geçiş ritüelleri" kuramının ve Victor Turner'ın ikinci aşama üzerine inşa ettiği "eşiksel" evrenin özelliklerini de barındırmaktadırlar. Bu kuramlar bağlamında yapılan değerlendirme, sahne sanatları temsillerinin ritüellerle benzeştiği fikrini pekiştirici niteliktedir. Sahne sanatları ve diğer sanat dallarının, 'insanı' içerisinde barındırdığı müddetçe sosyal bilimlerin yöntem ve kuramları ile anlaşılmaya elverişli olduğu açıktır. Bu araştırmanın kapsadığı alanın dışında kalan farklı unsurların gelecek çalışmalarla literatüre kazandırilması sevindirici olacaktır. 
Hakem Değerlendirmesi: Dış bağımsız.

Çıkar Çatışması: Yazar çıkar çatışması bildirmemiştir.

Finansal Destek: Yazar bu çalışma için finansal destek almadığını beyan etmiştir.

Peer-review: Externally peer-reviewed.

Conflict of Interest: The author has no conflict of interest to declare.

Grant Support: The author declared that this study has received no financial support.

\section{Kaynakça/References}

Brockett, O. G., \& Hildy, F. J. (2016). Tiyatro tarihi (Tufan Göbekçin, Çev.). İstanbul: Mitos-Boyut Yayınları.

Çalışlar, A. (1995). Tiyatro ansiklopedisi. Ankara: T.C. Kültür Bakanlığı Yayınları.

Güvenç, B. (1996). İnsan ve kültür. İstanbul: Remzi Kitabevi.

Haviland, W. A., Prins, H. E. L., Walrath, D., \& Mcbride, B. (2008). Kültürel antropoloji (İnan Deniz Erguvan Sarıŏlu, Çev.). İstanbul: Kaknüs Yayınları.

Kümbetoğlu, B. (2012). Sosyolojide ve antropolojide niteliksel yöntem ve araştırma. İstanbul: Bağlam Yayınları.

Neuman, W. L. (2006). Toplumsal araştırma yöntemleri: Nitel ve nicel yaklaşımlar. (Sedef Özge, Çev.). Ankara: Yayınodasi.

Özbudun, S., \& Uysal, G. (2012). 50 soruda antropoloji. İstanbul: Bilim ve Gelecek Kitaplı̆̆1.

Pavis, P., \& Shantz, C. (1999). Dictionary of the theatre: Terms, concepts, and analysis. Toronto ve Buffalo: University of Toronto Press.

Royce, A. P. (2004). Anthropology of the performing arts: Artistry, virtuosity, and interpretation in a cross-cultural perspective. Lanham, MD: AltaMira Press.

Small, M. E. (2000). Kinship Envy: Musings on the ties of blood and marriage. Natural History, 109, 88.

Turner, V. (1982). From ritual to theatre: The human seriousness of play. New York: PAJ Publications.

Turner, V. (1977). The ritual process: Structure and anti-structure. Ithaca: Cornell University Press.

Van Gennep, A. (1960). The rites of passage. Chicago: The University of Chicago Press. 